\title{
Sustainable Development as a Global Trend and an Economic Priority for the Nation
}

\author{
Peter Bindzar ${ }^{1, *}$, Shuxun Sang ${ }^{2}$, Eyvaz Gasanov ${ }^{3}$, and Rauf Aliyarov ${ }^{4}$ \\ ${ }^{1}$ Technical University of Kosice, Faculty of Mining, Ecology, Process Control and Geotech-nologies, \\ Letná 9, 04200 Kosice, Slovak republic \\ ${ }^{2}$ China University of mining and Technology, 100083 Xueyuan Road 11, Beijing, China \\ ${ }^{3}$ Khabarovsk State University of Economy and Law, Economics Department of International \\ Economic Relations Faculty, 680042134 Tikhookeanskaya st., Khabarovsk, Russia \\ ${ }^{4}$ Azerbaijan State University of Oil and Industry, Vice-Rector for Science and Technology, 16/21 \\ Azadlıq Av., Baku, Azerbaijan
}

\begin{abstract}
Today, it is important to consider the problems of preserving the environment from macroeconomic positions, which enable to determine the main systemic causes of environmental degradation; identify those economic directions that affect the environment. This approach is especially relevant for countries and regions that have a specialization in raw materials. Purely environmental measures aimed at preserving nature will not have an effect without an environmentally balanced macroeconomic policy, since without taking into account and correcting the development of the entire economy and its sectors (fuel, energy, metallurgy, agrarian, etc.), the effect of direct environmental investments will be minimal. It is obvious that without the access of the nation to the trajectory of sustainable development it is problematic to ensure a high quality of economic growth. However, we have to determine that resourceproducing countries and regions are following another way - first the economic growth, and then purification and restoration of the environment. Here the methodological basis can be the approaches developed by international organizations and initiative groups in the field of environmental protection.
\end{abstract}

\section{Introduction}

The concept of sustainable development, the main provisions of which were developed back in the 1950s of the last century, is one of the most striking examples of the ecosystem approach, it should be referred to the most relevant and controversial modern theories of human civilization development. Sustainable development has become a challenge for developed countries, as it demonstrated the need to form a new economic system, the distinctive feature of which should be the consideration of the environmental factor due to the widespread depletion of the planet's resource potential and environmental pollution. For the first time, the idea of negative changes in the environment on a global scale under the influence of human activity, the impossibility of successful social and economic

\footnotetext{
${ }^{*}$ Corresponding author: peter.bindzar@tuke.sk
} 
development separately from the environment quality were scientifically recognized. The theory caused a huge public response, its provisions were discussed at the international level, and the sustainable development of individual countries and regions became an important aspect of international cooperation.

\section{Materials and Methods}

The problem of sustainable development is largely due to the relationship to natural resources and environmental issues that prevailed in economic thought. Thus, classical economic schools (for example, A. Smith, D. Ricardo, A. Marshall) did not pay much attention to the environmental constraints in economic development [1-2]. As a result, until the 1950s and 1970s of the XX century the economic system called the "front economy" ("cowboy economy" by K. Boulding [2]) dominated in the world. It was based on the condition of unlimited natural resources and did not take into account environmental externalities. Its existence was possible as long as the economic growth due to low production volumes and greater opportunities for the biosphere self-regulation did not cause global environmental changes.

This situation changed at the turn of the XVII-XVIII centuries in connection with the industrial revolution. The first factor in the strengthening of environmental problems was the replacement of wood fuel by mineral, the most significant consequences were the following [2]:

- manual work was replaced by machine production; the rapid development of enterprises and the growth of cities began; other social classes with a special relation to nature appeared;

- energy based on mineral fuel caused a noticeable imbalance in the chemical and thermal state of the biosphere due to the emission of huge energy amounts.

The second factor is the process of globalization, which acquired a significant scale after the Second World War. The negative impact of globalization on the environment is a significant increase in the anthropogenic impact on natural ecosystems as a result of increased production (approximately 6 times over the period 1950-2000). At the same time, the qualitative transition of environmental problems to a new level took place due to the large number of insecure natural ecosystems. As a result, since the 1960s - 1970s environmental changes under the influence of man have become global, i.e. affecting all countries of the world without exception. Among these changes the most relevant are [3-4]:

- climate change on the Earth;

- air pollution;

- destruction of the ozone layer;

- depletion of freshwater resources and pollution of the World Ocean waters;

- land pollution, destruction of soil cover;

- impoverishment of biological diversity, etc.

The need to develop steadily was substantiated in the works of the Rome Club, among which the most famous and discussing is the report "Limits of Growth" (1972), prepared under the leadership of D. Meadows. The main conclusions of the report are the following [5]:

First, if current trends in population growth, industrialization, food production, environmental pollution and depletion of resources continue, the world will approach the limits of growth during the next century. As a result, most likely, there will be an unexpected and uncontrollable decline in the population and production will drop sharply.

Secondly, it is possible to change the growth trends and come to a sustainable long-term economic and environmental stability. The state of global equilibrium can be established at a level that allows satisfying the basic material needs of each person and gives each person 
equal opportunities for realizing personal potential.

Thirdly, the results described in the report were largely confirmed by the materials of the Stockholm Conference on Environment and Development Ecology (June 5-16, 1972). At the conference, not only the depletion of natural resources was noted (in some countries, even drinking water supply), but also the harmful effects of environmental pollution on the health of large human populations - the widespread occurrence of cancer, cardiovascular, pulmonary, gastrointestinal and allergic diseases, not to mention the numerous cases of direct poisoning.

\section{Results and Discussion}

Among the problems associated with climate change of the planet, one of the most relevant is the "glasshouse effect" - an increase in the concentration of greenhouse gases in the atmosphere resulting from the combustion of fossil fuels, associated gas in places of production, on the one hand, and a reduction in the quantity of gas regulation in the air due to deforestation and land degradation, on the other. Over the past 150 years, the carbon dioxide content in the atmosphere has increased by $30 \%$, its further accumulation for 40-50 years can increase the Earth's temperature by $2-4^{\circ} \mathrm{C}$, which can lead to melting of ice and rising the World Ocean levels and, as a result, flooding of a number of coastal zones. At the same time, it is worth noting the presence of another point of view, according to which climate warming is associated not with an increase in the concentration of carbon dioxide in the atmosphere, but with the rhythms of solar activity and the consequent climatic cycles on the Earth [6].

However, in view of the discrepancy between the dynamics of key climate indicators and models which do not take into account anthropogenic impact as a factor of climate change, the most likely is the anthropogenic nature of global warming. The problem is the destruction of the ozone layer as a result of air emissions of a number of gases, primarily freon gases. So, about $40 \%$ of freon gases are thrown into the atmosphere of the USA, $40 \%$ - by EU countries, $10 \%$ by Japan and less than $8 \%$ by Russia. Together with nitrous oxide, freon gases by organochloride compounds are getting into the upper layers of the atmosphere, destroy the ozone layer, creating the so-called "ozone hole", the area of which is currently estimated at about 5 million $\mathrm{km}^{2}$ [6]. Thinning of the ozone layer is one of the factors increasing the number of tumor diseases, which negatively affects the standard of living of the population and the quality of labor resources. In general, climate change leads to an increase in the frequency and intensity of extreme natural and climatic phenomena: droughts, floods, tornadoes, sharp thaws and frosts that cause significant damage to nature, man and the economy of countries.

Since the 1990s, the EU's environmental policy has made a shift away from direct administration to more flexible, including market elements mechanisms (for example, to the trade in greenhouse gas emissions quotas and to elements of participatory management based on the principle of "shared responsibility" between participants - government, business, the public, consumers). Moreover, under the Aarhus Convention, signed in 1998, private citizens should also be included in environmental activities, involved in the monitoring and control of violations of environmental standards. Citizens have the right to information, participation in the preparation of legal acts, initiation of legal action for environmental protection.

Flexible market mechanisms are effective for applying in all priority areas of environmental policy: in combating climate change and for preserving biological diversity, in protecting the environment and human health, in ensuring the sustainable use of natural resources. Thus, market instruments encourage producers and consumers to change behavior in favor of efficient use of natural resources, as well as the development of 
innovative environmental technologies. In addition, the proposed mechanisms meet the objectives of sustainable development and the Lisbon program.

Based on the report of the European Environment Agency, the following classification of modern operating market instruments can be given:

- trade permissions introduced to reduce emissions: emission quotas (CO2) or the conservation of natural resources (e.g., fish catch quotas);

- environmental taxes introduced to change prices and, thus, consumer and producer policies;

- environmental payments introduced to fully or partially cover the costs of environmental services, measures to reduce water pollution, landfilling;

- environmental subsidies and incentives to stimulate the development of new technologies, create new markets for environmental goods and services, to support the achievement of high levels of environmental protection by companies;

- schemes of liability and compensation, the purpose of which is to provide adequate compensation for damage from the consequences of activities dangerous for the environment, the costs of preventing and restoring damage.

Practical experience clearly shows that the greatest efficiency is achieved when using a combination of these tools. At the same time, the share of market instruments has increased significantly since the mid-1990s, especially for taxes, contributions and trade permissions. Most of the measures did not go beyond the EU, including ten new member countries, associated and transitional states of Central and Eastern Europe. The amounts of payment and contributions for water and air pollution were calculated in accordance with the ability of each of these countries to pay. Some countries have voluntarily agreed to impose taxes on waste and resource use.

Environmental priorities are reflected in the Concept of Long-Term Social and Economic Development of the Russian Federation until 2020. The priorities of this concept, officially approved by all power structures, should set the direction of the country's development for the long term. The aim of environmental policy is to significantly improve the quality of the natural environment and the environmental conditions of human life, to create a balanced, environmentally oriented model of economic development and environmentally competitive production.

The Concept identifies four main directions for the ecologization of economic development and the improvement of the ecological environment of a person's life for the future.

The first direction, related to the production ecologization, provides a gradual reduction of environmental impact levels from all anthropogenic sources. The main elements of this direction should be a new system of standardizing the permissible environmental impact, which provides the refusal to establish individual permissions for each enterprise. It will set standards and plans for a gradual reduction of pollution to the level corresponding to the best environmentally safe world technologies, the establishment of a developed waste disposal industry and expansion use of alternative renewable energy sources, control of anthropogenic emissions and greenhouse gases. Processes of production modernization, aimed at reducing energy intensity and material consumption, will be actively stimulated. The target is to reduce specific levels of environmental impact by 3-7 times, depending on the industry, by 2020.

The second direction - "Human Ecology", i.e. creation of ecologically safe and comfortable environment for living of people, places of work and rest, other social activity.

The third direction - "Environmental Business" - implies the creation of an effective environmental sector of the economy. This sector can include a competitive business in the field of general and specialized engineering, business development, environmental consulting, and development of the market for emission quotas. 
The fourth direction is "Conservation and protection of environment". The basis of this direction will be new methods of spatial planning, land use and development, taking into account environmental constraints.

In addition, carrying out environmentally balanced economic reforms and creating an appropriate economic environment at the macroeconomic level is important for the implementation of environmental policy. The state through macroeconomic policies can facilitate the transition to sustainable development. To conduct effective environmental and economic policy it is important to understand the level and co-ordination of the activities carried out, the scale and limits of their impact. There are two groups of activities:

- macroeconomic and sectoral measures;

- activities that have a proper environmental focus (targeted environmental measures).

The first group of macroeconomic/sectoral activities includes measures that take place throughout the economy or at the sector/complex level. They may not have explicit environmental objectives.

Among such measures it is possible to identify: structural reorganization of economy; reduction of the state budget deficit; financial and credit policy; regulation of foreign trade conditions; a tax or subsidy program in the main sectors of the economy (energy, agriculture, industry); the creation of conditions for investments, including foreign ones, etc.

All these activities, mechanisms and reforms have a greater or lesser impact on the state of the environment.

At the same time, it is rather difficult to single out "clean" negative and positive examples of the environmental impact of macroeconomic and sectoral policies. In real economic reality, activities often give a mixed ecological effect. Thus, measures aimed at macroeconomic stabilization can bring certain environmental benefits. But even in this case the effect depends on the fact that stability is achieved (the process can be temporary and with serious consequences for nature). To control these processes, environmental factors must be taken into account. Economic instability, unpredictability of the development of the economic situation, high inflation and interest rates, etc. contribute to "anti-sustainable" economic development, lead to increased exploitation of natural resources, saving on environmental costs.

\section{Conclusion}

Thus, summing up, it can be mentioned that sustainable development as a strategic direction of human civilization development has become a response to the global challenges that have emerged as a result of the deterioration of the environment, increased social and economic differentiation of countries, increased poverty of the population and a number of other reasons. The theory of sustainable development is, in our opinion, a logically consistent continuation of the doctrine of the noosphere, according to which, at the present geological stage, within the framework of his development, a person goes beyond the biosphere itself.

\section{References}

1. J. S. Hacker, G. A. Huber, Ph. Rehm, M. Schlesinger, R. Valletta, The Rockefeller Foundation, 6 (2010)

2. J. G. Fernald, C. I. Jones, American Economic Review, 104(5), 44-49 (2014)

3. S. Zhironkin, M. Gasanov, G. Barysheva, E. Gasanov, O. Zhironkina, G. Kayachev, E3S Web of Conferences, 21, 04002 (2017) 
4. M. Prokudina, O. Zhironkina, O. Kalinina, M. Gasanov, F. Agafonov, E3S Web of Conferences, 21, 04003 (2017)

5. J. S. Hacker, G. A. Huber, A. Nichols, Ph. Rehm, S. Craig, The Rockefeller Foundation, 6 (2012)

6. S. Zhironkin, M. Gasanov, G. Barysheva, E. Gasanov, O. Zhironkina, G. Kayachev, E3S Web of Conferences, 21, 04002 (2017) 